\title{
Haemoptysis after breath-hold diving
}

\author{
A. Boussuges*, C. Pinet ${ }^{+}$, P. Thomas ${ }^{+}$, E. Bergmann*, J-M. Sainty*, D. Vervloet ${ }^{+}$
}

\begin{abstract}
Haemoptysis after breath-hold diving. A. Boussuges, C. Pinet, P. Thomas, E. Bergmann, JM. Sainty, D. Vervloet. C) ERS Journals Ltd 1999.

ABSTRACT: Pulmonary oedema has been described in swimmers and self-contained underwater breathing apparatus (Scuba) divers. This study reports three cases of haemoptysis secondary to alveolar haemorrhage in breath-hold divers. Contributory factors, such as haemodynamic modifications secondary to immersion, cold exposure, exercise and exposure to an increase in ambient pressure, could explain this type of accident. Furthermore, these divers had taken aspirin, which may have aggravated the bleeding.
\end{abstract}

Eur Respir J 1999; 13: 697-699.

\begin{abstract}
*Service de Réanimation Médicale, Hôpital Salvator, Marseille, France. ${ }^{+}$Dept des Maladies Respiratoires, Hôpital Sainte Marguerite, Marseille, France.
\end{abstract}

Correspondence: A. Boussuges, Service de Réanimation Médicale et d'Hyperbarie, Hôpital Salvator, 249 Boulevard de SainteMarguerite, BP 51, 13274 Marseille Cédex 09, France. Fax: 33491745435

Keywords: Alveolar haemorrhage, apnoea, diving, haemoptysis, pulmonary oedema

Received: May 51998

Accepted after revision August 131998
Pulmonary oedema has been described in swimmers and self-contained underwater breathing apparatus (Scuba) divers [1-4], but there is only one case report in a breath-hold diver [5]. This study reports three cases of haemoptysis secondary to alveolar haemorrhage in breath-hold divers during underwater fishing.

\section{Case studies}

Case 1

An experienced 24-yr-old breath-hold diver was admitted to the intensive care unit of a university hospital for respiratory distress which had occurred during an underwater diving expedition. The clinical distress appeared $1 \mathrm{~h}$ after entering the water, after many dives to a depth of 25 metres of sea water (msw) followed by a rapid rise to the surface. He experienced dyspnoea, coughing and expectorated reddish froth. The subject's haemoglobin was 10.5 $\mathrm{g} \cdot 100 \mathrm{~mL}^{-1}$, and his platelet count and coagulation results were normal. With $10 \mathrm{~L} \cdot \mathrm{min}^{-1}$ oxygen, his arterial oxygen tension $\left(\mathrm{Pa}, \mathrm{O}_{2}\right)$ was $14.6 \mathrm{kPa}(110 \mathrm{mmHg})$ and arterial carbon dioxide tension $\left(\mathrm{Pa}_{\mathrm{a}} \mathrm{CO}_{2}\right) 4.5 \mathrm{kPa}(34 \mathrm{mmHg})$. He was treated with continuous positive airway pressure and diuretics. A thoracic computed tomography (CT) scan (volumic spiral acquisition) showed disseminated alveolar opacification (fig. 1). Within $36 \mathrm{~h}$ the patient's status had improved considerably, allowing his transfer to the respiratory disease department. A bronchoalveolar lavage (BAL) was performed and a pinkish fluid was collected. Analysis showed $7 \times 10^{6}$ red cells $\cdot \mathrm{mL}^{-1}$ and the macrophages did not have an increased haemosiderin content, compatible with recent alveolar haemorrhage. The patient was questioned and stated that he had taken $1 \mathrm{~g}$ of aspirin a few hours before diving, with the intention of improving his performance. Pulmonary function tests and the transthoracic echocardiogram performed 1 week after the event were both normal.
Case 2

A 35-yr-old male performed intensive breath-hold dives during an international underwater fishing competition in the Mediterranean. The mean depth for breath-hold dives was $\sim 25 \mathrm{msw}$. The duration of apnoea was 2 min with a 1:1 ratio of time spent on the surface to time spent at depth. Two hours after the start of the competition, he developed a productive cough with haemoptysis. One day later, because the cough persisted, he sought medical evaluation. The physical examination was normal, but the chest radiograph demonstrated interstitial pulmonary oedema. The coagulation results were normal. Four days after the haemoptysis, a BAL was performed, revealing many siderophages (Golde's score: 140) [6]. No treatment was required and his cough resolved spontaneously. When the patient was questioned, he stated that he had taken $1 \mathrm{~g}$ of aspirin daily during the 3 days of underwater fishing competition for the prevention

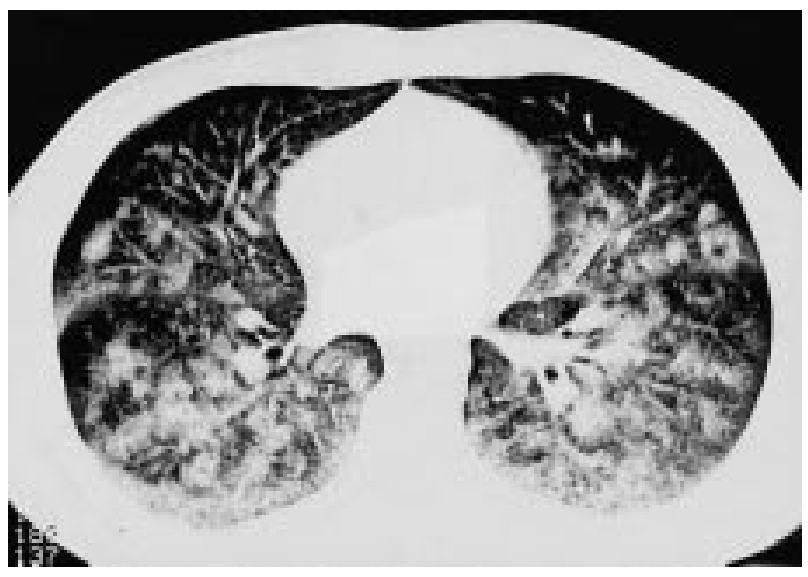

Fig. 1. - Thoracic computed tomography scan showing disseminated alveolar opacification. 
of headache. The patient was discharged from the hospital feeling well and with a normal clinical evaluation.

Case 3

A 28-yr-old male, a well-trained breath-hold diver, experienced a mild cough and haemoptysis after intensive periods of underwater fishing dives (depth of dives $\sim 35$ msw, duration of apnoea between $45 \mathrm{~s}$ and $2 \mathrm{~min}$ ). These symptoms disappeared within a few hours and he did not seek medical help. He was taking $500 \mathrm{mg}$ of aspirin before any breath-hold diving, believing that this medication would improve his performance. He sought medical evaluation 2 weeks later. The chest radiograph, CT scan and physical examination were unremarkable. Furthermore, resting echocardiogram demonstrated normal left ventricular systolic and diastolic function. The coagulation tests were normal. In this context, pulmonary embolism was thought to be unlikely.

The subject had a prior history of dyspnoea and haemoptysis after breath-hold diving 7 yrs earlier. The fibreoptic bronchoscopy performed after this accident was macroscopically normal and a BAL was grossly bloody with $3 \times 10^{6}$ red cells $\cdot \mathrm{mL}^{-1}$ without siderophages.

A summary of the three observations is presented in table 1 .

\section{Discussion}

This is the first published case series of nonfatal alveolar haemorrhage in breath-hold divers. Only one case has been reported previously [5]. None of the divers had presented with water aspiration. Haemoptysis could be explained by cardiovascular changes during immersion and apnoea $[7,8]$. Head-out immersion in water produces profound changes in cardiovascular function, including increases in intrathoracic blood volume and cardiac output. Three major factors are responsible for these changes: the high density of the medium (the water) in which the extrathoracic vessels are supported (analogous to a gravityfree state), the differential pressure distribution over the body (giving rise to a negative pressure breathing) and the high thermoconductivity of the medium. WILMSHURST et al. [1] attributed pulmonary oedema observed in Scuba divers to haemodynamic modifications, secondary to immersion and exposure to cold. During breath-hold diving, other factors can explain haemorrhage. Ambient pressure in-

Table 1. - Characteristics of the breath-hold divers

\begin{tabular}{lrrr}
\hline & Diver 1 & Diver 2 & Diver 3 \\
\hline Age yrs & 24 & 35 & 28 \\
Height cm & 178 & 172 & 168 \\
Weight kg & 66 & 64 & 72 \\
Diving suit & Yes & Yes & Yes \\
Dive depth msw & 25 & 25 & 35 \\
Water temperature (surface) ${ }^{\circ} \mathrm{C}$ & 25 & 18 & 24 \\
Lung function tests & & & \\
$\quad$ TLC L & 7.23 & 7.07 & 6.34 \\
RV L & 1.63 & 1.27 & 1.45 \\
RV/TLC \% & 22 & 18 & 23 \\
\hline
\end{tabular}

TLC: total lung capacity; RV: residual volume; msw: metre of sea water. creases proportionately to depth and the air in the lungs adapts to the effect of this increase in pressure by decreasing in volume (Boyle-Mariotte law). When the pulmonary volume is reduced to residual volume, intrathoracic pressure is equal to hydrostatic pressure. Below this threshold, the volume can no longer decrease because of the rigidity of the thorax; thus, intrathoracic pressure decreases, leading to a further blood shift towards the chest $[9,10]$. The volume of blood displaced is proportional to the depth of the dive and is held in the pulmonary circulation for as long as the intrathoracic pressure is not in equilibrium with the hydrostatic pressure surrounding the diver. It has been found that the blood shift is close to $1 \mathrm{~L}$ around a depth of $30 \mathrm{msw}$ [9]. All of these phenomena cause an elevation in the transpulmonary capillary wall pressure. WeSt and MATHIEU-Costello [11] described ultrastructural modifications to pulmonary capillary walls when they were submitted to an increase in transmural pressure. Such modifications may predispose to alveolar haemorrhage. The increase in pressure leads to a fluid shift, displacing it from the capillary lumen to the alveolar interstitium, then into the alveoli. If the pressure gradient continues to rise, pulmonary oedema and alveolar haemorrhage may develop.

The incidence of these accidents is difficult to assess because divers with minor haemorrhage (e.g. case number 3) may not seek medical attention. However, fatal accidents have been reported in the past and could have a similar pathogenesis, such as thoracic squeeze [12].

In sports medicine, alveolar haemorrhage has been described in rugby players [13] and elite athletes [14]. The bleeding is secondary to the abrupt increase in pulmonary vascular pressure observed during exercise. A similar mechanism could be involved in the haemorrhage observed in healthy people during strenuous swimming [4].

In the present series, the divers had ingested aspirin, which may have aggravated the bleeding through its antiplatelet effect. Aspirin is often taken by underwater fishing divers in Europe. It is used as a painkiller and because it is believed to increase the diver's performance. Because of the potential risk of alveolar haemorrhage, the use of aspirin by breath-hold divers is inadvisable.

\section{References}

1. Wilmshurst PT, Nuri M, Crowther A, Webb-Peploe MM. Cold-induced pulmonary oedema in scuba divers and swimmers and subsequent development of hypertension. Lancet 1989; i: 62-65.

2. Hampson NB, Dunford RG. Pulmonary oedema of scuba divers. Undersea Hyperbaric Med 1997; 24: 29-33.

3. Pons M, Blickenstorfer D, Oechslin E, et al. Pulmonary oedema in healthy persons during scuba-diving and swimming. Eur Respir J 1995; 8: 762-767.

4. Weiler-Ravell D, Shupak A, Goldenberg I, et al. Pulmonary oedema and haemoptysis induced by strenuous swimming. BMJ 1995; 311: 361-362.

5. Boussuges A, Succo E, Bergmann E, Sainty M. L'hémorragie intra-alvéolaire: un accident inhabituel chez un plongeur en apnée. Presse Med 1995; 24: 1169-1170.

6. Golde DW, Drew WL, Klein HZ, Finley TN, Cline MJ. Occult pulmonary haemorrhage in leukaemia. $B M J 1975$; ii: $166-168$.

7. Ferrigno $\mathrm{M}$, Hickey DD, Liner $\mathrm{MH}$, Lundgren $\mathrm{CE}$. 
Simulated breath-hold diving to 20 meters: cardiac performance in humans. J Appl Physiol 1987; 62: 2160-2167.

8. Liner MH. Cardiovascular and pulmonary responses to breath-hold diving in humans. Acta Physiol Scand 1994; 151: Suppl. 620, 1-32.

9. Schaefer KE, Allison RD, Dougherty IH Jr, et al. Pulmonary and circulatory adjustments determining limits of depths in breath-hold diving. Science 1968; 162: 10201023.

10. Craig AB Jr. Depth limit of breath-hold diving. Respir Physiol 1968; 5: 14-22.

11. West JB, Mathieu-Costello O. Stress failure of pulmonary capillaries: role in lung and heart disease. Lancet 1992; 340: 762-767.

12. Strauss MB, Wright PW. Thoracic squeeze diving casualty. Aerospace Med 1971; 42: 673-675.

13. West JB, Mathieu-Costello O. Geddes DM. Intrapulmonary hemorrhage caused by stress failure of pulmonary capillaries during exercise (Abstract). Am Rev Respir Dis 1991; 143: A569.

14. Hopkins SR, Schoene RB, Henderson WR, Spragg RG, Martin TR, West JB. Intense exercise impairs the integrity of the pulmonary blood-gas barrier in elite athletes. Am J Respir Crit Care Med 1997; 155: 1090-1094. 